Research Paper

\title{
Fangchinoline protects against bone loss in OVX mice via inhibiting osteoclast formation, bone resorption and RANKL-induced signaling
}

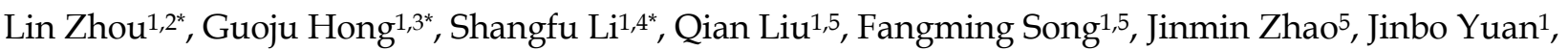 \\ Jennifer Tickner ${ }^{1}$, Jiake $\mathrm{Xu}^{1 凶}$ \\ 1. School of Biomedical Sciences, The University of Western Australia, Perth, Western Australia, 6009, Australia \\ 2. Department of Endocrinology, The Fifth Affiliated Hospital, Guangzhou Medical University, Guangzhou, 510700, China. \\ 3. Orthopedic Department, The First Affiliated Hospital of Guangzhou University of Chinese Medicine, Guangzhou 510006, China. \\ 4. Department of Spine Surgery, the Third Affiliated Hospital of Sun Yat-sen University, Guangzhou Guangdong, 510630, P. R. China. \\ 5. Research Centre for Regenerative Medicine and Guangxi Key Laboratory of Regenerative Medicine, Guangxi Medical University, Guangxi, 530021, China \\ *Authors equally contributed to this work. \\ $\square$ Corresponding author: Jiake Xu, E-mail: jiake.xu@uwa.edu.au
}

(c) The author(s). This is an open access article distributed under the terms of the Creative Commons Attribution License (https://creativecommons.org/licenses/by/4.0/). See http://ivyspring.com/terms for full terms and conditions.

Received: 2019.06.01; Accepted: 2019.09.13; Published: 2020.01.01

\begin{abstract}
Osteoporosis is a disease characterized by abnormally increased formation and function of osteoclasts. Anti-RANKL treatment using natural medicine is a potential therapy for osteoporosis. Here, we studied the effect of fangchinoline, which is extracted from the root of Stephania tetrandra $\mathrm{S}$. Moore, on osteoclast formation and function. We found that fangchinoline inhibited osteoclastogenesis at doses of 0.5 and $1 \mu \mathrm{M}$. In addition, we also examined the mechanism of the inhibitory effect of fangchinoline on osteoclasts. We found that fangchinoline down regulated NFATcl activity and expression. However, fangchinoline did not affect IKBa degradation and MAPK pathways. In addition, we also found that fangchinoline could protect against bone loss in OVX mice. Taken together, fangchinoline may be a potential compound for osteoporosis.
\end{abstract}

Key words: fangchinoline, RANKL, osteoclast, NF-KB, NFATc1, MAPK

\section{Introduction}

Bone is a hard tissue that forms the endoskeleton of vertebrates. It is a dynamic tissue that goes through a continuous process of remodelling and renewing to maintain internal homeostasis throughout life (1). Osteoclast-induced bone resorption and osteoblastinduced bone formation are two critical components for this process. Increased numbers and overactivity of osteoclasts is a leading cause of osteoporosis, which is the most common bone disorder in elderly people(2). Osteoclasts, giant multinucleated cells, are derived from hematopoietic stem cells. The formation and differentiation of osteoclasts requires two key cytokines, receptor activator of nuclear factor kappa-B ligand (RANKL) and macrophage colony-stimulating factor (M-CSF). The interaction of RANKL and its receptor RANK activates a series of signalling pathways including NF-kB, MAPKs and NFAT pathways (3). RANKL- targeted treatment has become a new promising option for osteoclast-related bone diseases.

Fangchinoline is a bisbenzylisoquinoline alkaloid derived from the root of Menispermaceae family such as Stephania tetrandra S. Moore and Cyclea peltata Diels (4). Fangchinoline has numerous pharmacological properties such as anti-inflammatory, antioxidant, and neural protection effects (5-7). Tetrandrine, an analogue of fangchinoline, was found to inhibit osteoclast formation and function in cell culture and in a sciatic-neurectomized mouse model (8). However, the role of Fangchinoline in bone resorption and its therapeutic effects on osteoporosis are not known. 
In this study, we examined the inhibitory effect of fangchinoline on osteoclast formation, bone resorption. In addition, we investigated the role of fangchinoline in osteoclast marker gene expression and RANKL-induced signalling pathways. Further, we explored the therapeutic potential of fangchinoline using an OVX mouse model. Collectively, we found that fangchinoline protects against bone loss in OVX mice via inhibiting osteoclast formation, bone resorption and RANKL-induced activity.

\section{Materials and Methods}

\section{Materials}

Fangchinoline with a purity $\geq 98 \%$ was purchased from Mansite (Chengdu, China). Alpha modified Minimal Essential Medium (a-MEM) and fetal bovine serum (FBS) were purchased from Thermo Fisher Scientific (Scoresby, Australia). Penicillin- Streptomycin and GlutaMAX were purchased from Thermo Fisher Scientific (Scoresby, Australia). The production and purification of recombinant RANKL were described in a previous study (9). Antibodies to IKBa (C21), phosphorylated ERK, phosphorylated P38, NFATc1 (7A6) and $\beta$-actin were obtained from Santa Cruz Biotechnology (Paso Robles, CA, USA). Antibodies to P38, phosphorylated JNK and JNK were ordered from Cell signaling (Danvers, MA, USA). Antibody to ERK, MTS and luciferase assay kits were purchased from Promega (Madison, WI, USA). Antibody to v-ATPase-d2 was produced as reported previously (10).

\section{Osteoclastogenesis assay}

Freshly isolated bone marrow macrophages (BMMs) from C57BL/ 6 mice were plated in T75 flasks and cultured in a-MEM supplemented with M-CSF (50 ng/ml). When cells were confluent, BMMs were seeded in 96-well plates at the concentration of $6 \times 10^{3}$ cells per well. After overnight incubation to allow attachment, cells were differentiated with RANKL (50 $\mathrm{ng} / \mathrm{ml}$ ) and incubated with different concentrations of fangchinoline. Medium was changed every two days for 5 days or until mature osteoclasts were formed. For investigating which stage of osteoclastogenesis is mostly affected by fangchinoline, BMMs were treated with RANKL (50 ng/ml) for 5 days, while $1 \mu \mathrm{M}$ fangchinoline was added to BMM at either day 1,3 or 5 . Then, the cells were fixed in paraformaldehyde for $10 \mathrm{~min}$, followed by three washes with $1 \times$ PBS. After that, the cells were stained with TRAcP staining buffer for counting multinucleated cells and image acquired using a light microscope.

\section{MTS assay}

BMMs were seeded into 96-well plates at the density of $6 \times 10^{3}$ cells per well and cultured in a-MEM with M-CSF for overnight incubation. BMMs were then incubated with different concentrations of fangchinoline for $48 \mathrm{~h}$. After that, the cells were treated with $20 \mu \mathrm{l}$ of MTS solution (Promega, Madison, WI, USA) for $2 \mathrm{~h}$, and then absorbance read with a microplate reader (Bio-Rad, Hercules, CA, USA) at $490 \mathrm{~nm}$.

\section{Hydroxyapatite resorption assay}

The effect of fangchinoline on activity of osteoclasts was tested by hydroxyapatite resorption assay. BMMs were seeded in 6-well collagen-coated plates $\left(1 \times 10^{5} /\right.$ well $)$ for overnight incubation. Then, the cells were stimulated with RANKL $(50 \mathrm{ng} / \mathrm{ml})$ for every two days until osteoclasts began to form. After that, the cells were harvested with cell dissociation solution and cultured in hydroxyapatite-coated 96 well plates (Corning, Sullivan Park, NY, USA). Cells were treated with RANKL and fangchinoline for another $48 \mathrm{~h}$. Then, half of the wells were fixed with $2.5 \%$ glutaraldehyde and stained with TRAcP staining buffer for counting the number of multinucleated cells. The remaining wells were bleached with $10 \%$ bleaching solution for $10 \mathrm{~min}$ and then the images were taken for calculating resorbed area by ImageJ software.

\section{RNA isolation and analysis}

BMMs were seeded in 6-well plates at the density of $1 \times 10^{5}$ per well and stimulated with RANKL $(50 \mathrm{ng} / \mathrm{ml})$ and treated with fangchinoline in various concentrations for 5 days. Then total RNA was extracted by TRIzol Reagent according to the manufacturer's instructions (Life Technologies, Mulgrave, Australia). Single-stranded cDNA was synthesized from $1 \mu \mathrm{g}$ of RNA using reverse transcriptase with oligo-dT primer. The specific mouse primers used in $\mathrm{QPCR}$ reactions were designed as follows: mouse cathepsin $\mathrm{K}$ (Ctsk) (forward: 5'-GGG AGA AAA ACC TGA AGC-3'; reverse: 5'-ATT CTG GGG ACT CAG AGC-3'), mouse calcitonin receptor (Calcr) (forward: 5'-TGG TTG AGG TTG TGC CCA-3'; reverse: 5'-CTC GTG GGT TTG CCT CAT C-3'), V-ATPase-d2 (Atp6v0d2) (forward: 5'-GTG AGA CCT TGG AAG ACC TGA A-3'; reverse: 5'-GAG AAA TGT GCT CAG GGG CT-3'), matrix metallopeptidase 9 (MMP9) (forward: 5'-CGT GTC TGG AGA TTC GAC TTG A-3'; reverse: 5'-TTG GAA ACT CAC ACG CCA GA-3'), Nfatc1 (forward: 5'-CAA CGC CCT GAC CAC CGA TAG-3'; reverse: 5'-GGC TGC CTT CCG TCT CAT AGT-3'), TRAcP (Acp5) (forward: 5'-TGT GGC CAT CTT TAT GCT-3'; reverse: 5'-GTC ATT TCT TTG GGG CTT-3'), and Gapdh (forward: 5'-ACC ACA GTC CAT GCC ATC 
AC-3'; reverse: 5'-TCC ACC ACC CTG TTG CTG TA-3'). qPCR reactions were performed though ViiA $^{\text {TM }} 7$ Real-time PCR system (Applied Biosystems, Paisley, United Kingdom). All the qPCR reactions were run in triplicates, and normalized by housekeeping gene Gapdh and further normalized by control samples.

\section{NF-KB and NFAT luciferase reporter gene assay}

RAW264.7 cells stably transfected with an NF-kB luciferase reporter construct $(3 қ B-L u c-S V 40)$ (11) or with an NFATc1 luciferase reporter construct (12) were used in this experiment to determine the effect of fangchinoline on NF- $\mathrm{KB}$ and NFAT activation. Transfected cells were seeded in 48-well plates at the density of $1.5 \times 10^{5}$ cells/well (NF-kB luciferase reporter gene assay) or $5 \times 10^{4}$ cells/well (NFAT luciferase reporter gene assay). After overnight incubation, cells were pre-treated with fangchinoline for $1 \mathrm{~h}$, and then incubated with RANKL (50ng/ml) for $6 \mathrm{~h}$ (NF-kB luciferase reporter gene assay) or $24 \mathrm{~h}$ (NFAT luciferase reporter gene assay); respectively. Then, the cells were harvested and lysed for measuring luciferase activity using the luciferase assay system (Promega, Sydney, Australia) following the manufacturer's instruction.

\section{Western blot assays}

BMMs cells were seeded in 6-well plates overnight at the density of $1 \times 10^{6}$ cells per well. After $3 \mathrm{~h}$ serum starvation, cells were pre-treated with fangchinoline for $1 \mathrm{~h}$, then stimulated with RANKL for 0, 10, 20, 30 and $60 \mathrm{~min}$. For long time course western blot assay, cells were cultured in 6 -well plates at 1 $\times 10^{5}$ cells per well. Fangchinoline was added to the cells on the next day. Then, the cells were stimulated by RANKL at day 1,3 and 5. Cells were harvested and lysed by RIPA lysis buffer on ice. Protein samples were separated by SDS-polyacrylamide gel electrophoresis (SDS-PAGE) and transferred to nitrocellulose membranes. The membranes were blocked with $5 \%$ skimmed milk for at least $1 \mathrm{~h}$ at room temperature and then incubated with primary antibodies overnight at $4{ }^{\circ} \mathrm{C}$. After three times washing with $1 \times$ PBS, membranes were incubated with HRP-conjugated secondary antibodies for $1 \mathrm{~h}$. Proteins on the membranes were visualized by the enhanced chemiluminescence (ECL) system (Amersham Pharmacia Biotech, Sydney, Australia).

\section{Ovariectomy (OVX) animal model}

For OVX experiments, C57BL/ 6 mice were used in this study. The in vivo experiments were conducted according to the protocols proposed by The Guangxi
Medical University Ethics Committee [SCXK - (JUN) 2012-0004, China] and the University of Western Australia Animal Ethics Committee. All the mice were raised in standard cages, with the temperature set at $22^{\circ} \mathrm{C}$ and the lighting condition set at $12 \mathrm{~h}$ light and 12 $\mathrm{h}$ dark cycle. Mice aged 7-weeks were anesthetized with chloral hydrate and subjected to ovariectomy or sham operation. The ovariectomized (OVX) mice were assigned to four groups, including sham group, OVX group, OVX + fangchinoline $(1 \mathrm{mg} / \mathrm{ml})$ group, and OVX + fangchinoline $(5 \mathrm{mg} / \mathrm{ml})$ group. Each group contained six mice. In details, after one week to allow recovery from the surgery, OVX mice received intraperitoneal injection of fangchinoline at the concentration of $1 \mathrm{mg} / \mathrm{kg}$ and $5 \mathrm{mg} / \mathrm{kg}$ every two days. In the meantime, mice from OVX control group and sham operation group were injected with $10 \%$ DMSO for comparison. After six-weeks of treatment, all the mice were sacrificed and their femurs were removed for analyzing bone parameters by micro-CT and histomorphometric analysis.

\section{Micro-CT analysis}

The collected femurs were fixed with $4 \%$ paraformaldehyde (PFA) for $24 \mathrm{~h}$, followed by three washes with $1 \times$ PBS. Then, samples were scanned by a Skyscan 1176 micro-CT instrument (Bruker microCT, Kartuizersweg, Belgium), using $500 \mu \mathrm{A}$ source current, $50 \mathrm{kV}$ voltage and $0.5 \mathrm{~mm}$ aluminium filter. Raw images were reconstructed and analyzed using standardized parameters (13) with the accompanied programs (NRecon and CTAn, respectively). The regions of interest were set from 0.5 to $1.5 \mathrm{~mm}$ below the bottom of the growth plate. The following trabecular bone parameters were measured: bone volume/tissue volume (BV/TV), trabecular thickness (Tb.Th), trabecular number (Tb.N) and trabecular separation (Tb.Sp).

\section{Histomorphometric}

For histomorphometric study, the mouse femurs were decalcified and embedded with paraffin. The bone samples were sectioned ( $5 \mu \mathrm{m}$ thick) and stained by haematoxylin and eosin (H\&E) and TRAcP. The stained sections were then scanned with Aperio Scanscope, and analyzed with BIOQUANT OSTEO software (Nashville, USA).

\section{Statistical analysis}

All data demonstrated in this study are representative of one of three or more independent experiments. The data was expressed as mean \pm SEM. Statistical significance was determined by paired or unpaired Student's t-tests using Microsoft Excel 2010. 
$P$ value $<0.05$ was considered to be statistically significant.

\section{Results}

\section{Fangchinoline inhibits osteoclastogenesis}

To investigate the effect of fangchinoline treatment (Figure 1A) on osteoclast formation, BMM cells were incubated with different concentrations of fangchinoline $(0.125,0.25,0.5,1 \mu \mathrm{M})$ and RANKL $(50 \mathrm{ng} / \mathrm{ml})$ for 5 days. The results suggested that fangchinoline inhibited osteoclastogenesis at 0.5 and 1 $\mu \mathrm{M}$ in a dose-dependent manner (Figure 1B, C). To examine the time course effect of fangchinoline on osteoclastogenesis, $1 \mu \mathrm{M}$ fangchinoline was added to BMMs for 1, 3 or 5 days in the continuous presence of RANKL $(50 \mathrm{ng} / \mathrm{ml})$. Fangchinoline significantly inhibited osteoclastogenesis only when added during the early stages of culture (Figure 1D, E), suggesting that fangchinoline influenced early stages of the osteoclast formation process. MTS results showed that fangchinoline did not impact the viability of BMMs (Figure 1 F), which implied that the inhibitory effect of fangchinoline on osteoclasts was not caused by cytotoxicity.

\section{Fangchinoline reduces osteoclastic resorption}

To examine the effect of fangchinoline on osteoclasts function, hydroxyapatite-coated 96-well plates were used. Mature osteoclasts were incubated with fangchinoline $(0.5$ and $1 \mu \mathrm{M})$ on hydroxyapatite-coated 96-well plates for $48 \mathrm{~h}$, and the area resorbed per osteoclast was determined. From light microscopy, it was visible that hydroxyapatite resorption area was reduced by fangchinoline (Figure 2A). Consistently, the resorption area per osteoclast analysed by Image J was reduced by fangchinoline, while the osteoclast number was not significantly affected (Figure 2B, C).

\section{Fangchinoline suppresses the expression of osteoclast marker genes}

To investigate fangchinoline on RANKLinduced gene expression in osteoclasts, qPCR was employed. As shown in Figure 3, fangchinoline dose dependently reduced RANKL-induced osteoclast marker genes, including Ctsk, Calcr, Atp6v0d2, Mmp9, Nfatc1 and Acp5. This result is consistent with inhibitory effect of fangchinoline on the osteoclast formation and function.
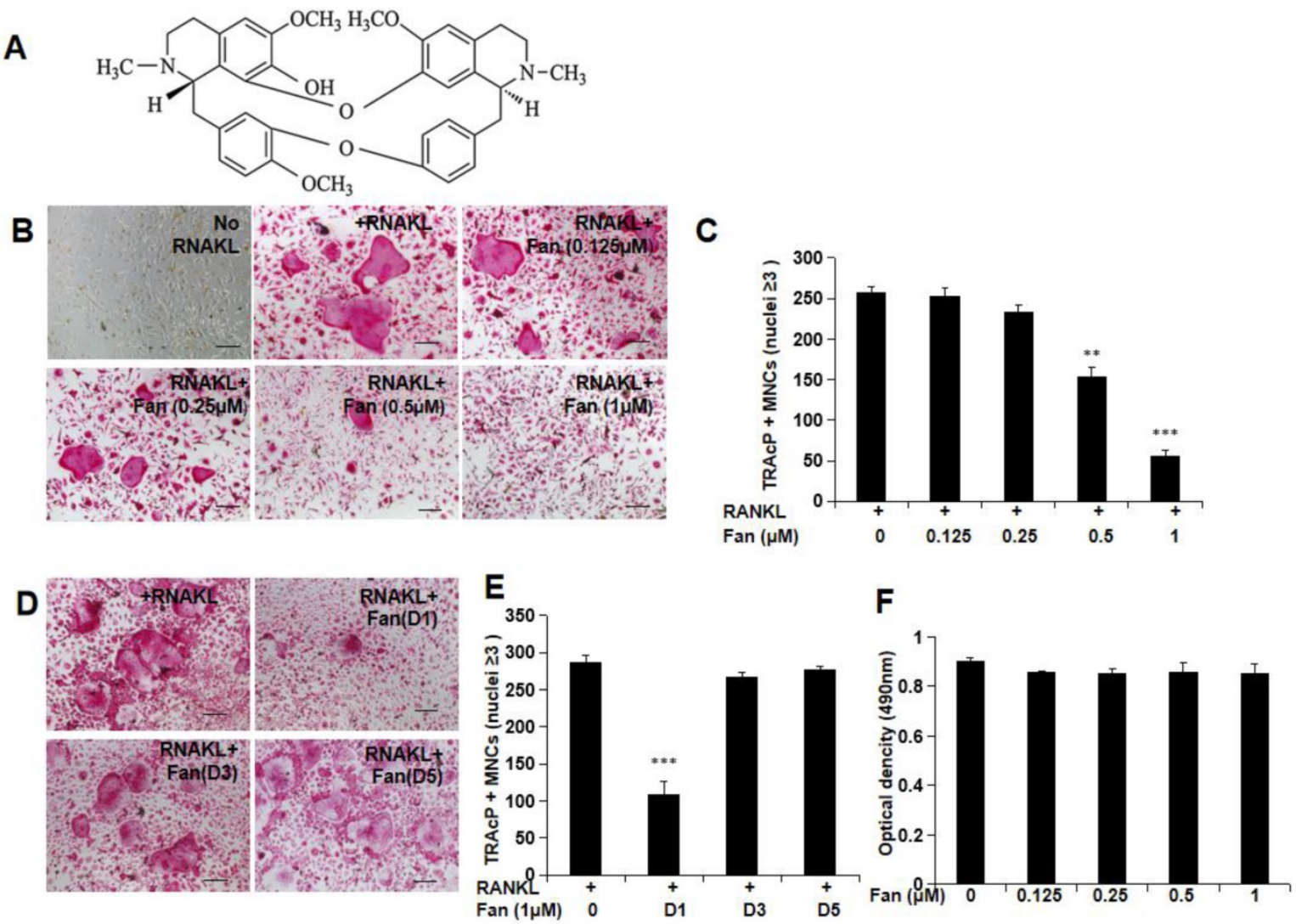

Figure 1. Osteoclastogenesis and MTS assay. (A) Chemical structure of fangchinoline. (B) RANKL-induced osteoclastogenesis was suppressed by fangchinoline in a dose dependent manner, which was visualised by light microscope. (scale bars $=100 \mu \mathrm{m})(\mathrm{C})$ Consistently, the number of multi-nucleated cells $(\geq 3$ nuclei) was significantly decreased from $0.5 \mu \mathrm{M}$ by counting under optical microscopy. (D) Osteoclast images showed that the treating of fangchinoline at day 1 inhibited osteoclastogenesis. (scale bars $=100 \mu \mathrm{m})(\mathrm{E})$ Multi-nucleated cells $(\geq 3$ nuclei) counting also showed that fangchinoline inhibited osteoclastogenesis mainly at day 1 . (F) MTS results indicated that fangchinoline didn't affect cell viability. $* * P<0.01, * * * P<0.001$ relative to fanchinoline-untreated controls. 
A
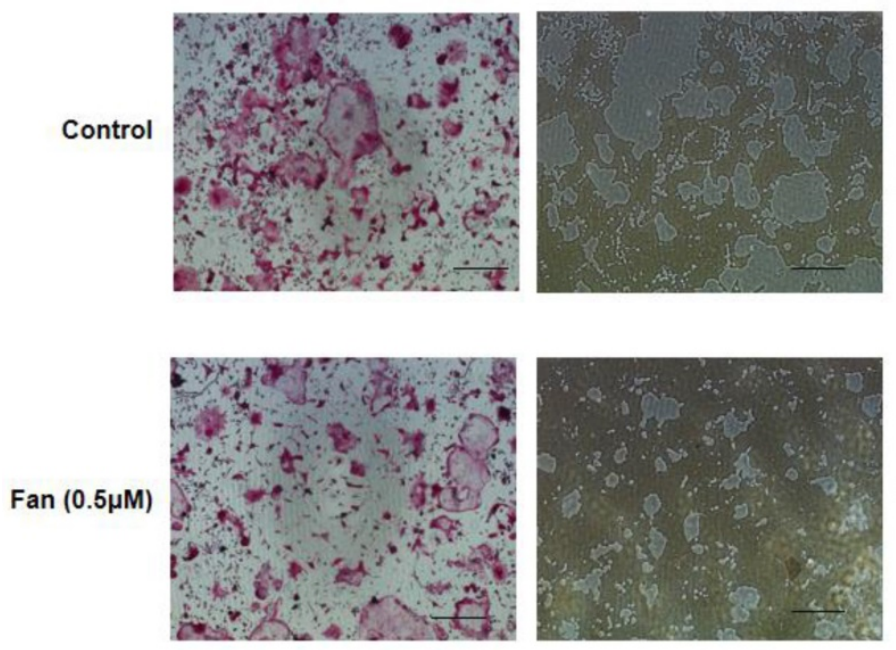

Fan $(1 \mu \mathrm{M})$

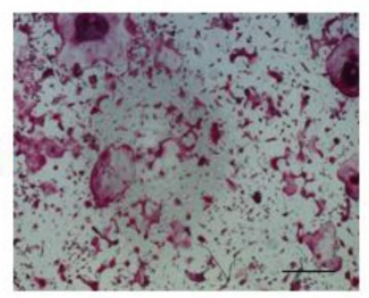

B

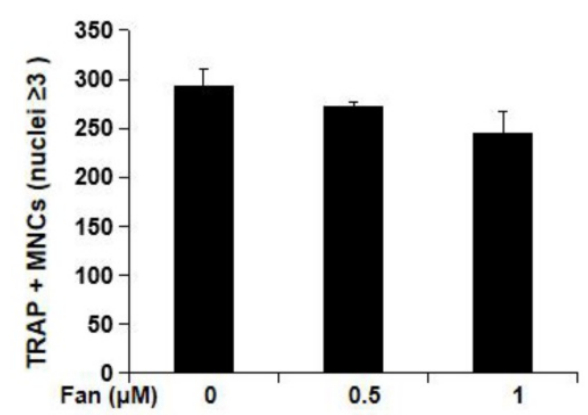

C

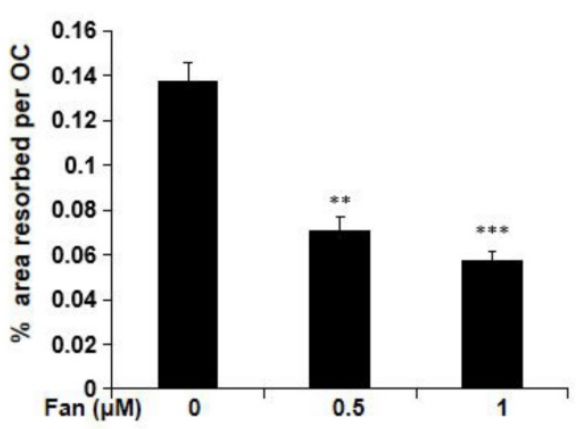

Figure 2. Resorption assay. (A) Visualized TRAcP positive multinucleated cells (left side) and resorption pits (right side) on hydroxyapatite-coated plates (scale bars, $500 \mu \mathrm{m})$. (B) Fangchinoline didn't affect osteoclast ( $\geq 3$ nuclei) number. (C) Pits area of per osteoclast was significantly decreased upon the treatment of fangchinoline in a dose-dependent manner on hydroxyapatite-coated plates. $* * P<0.01, * * * P<0.001$ relative to fanchinoline-untreated controls.

Cathepsin K

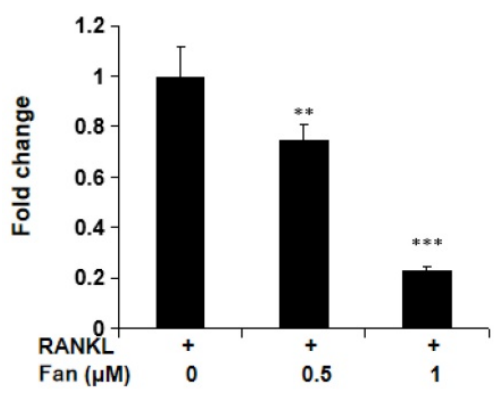

MMP9

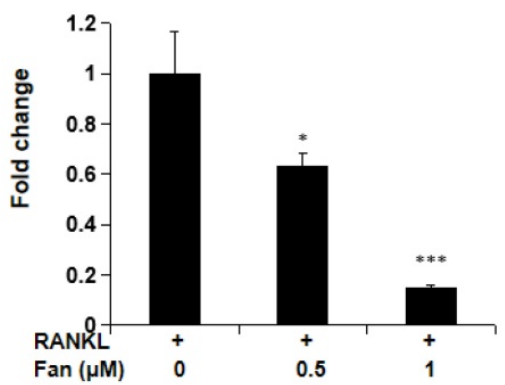

Calcitonin Receptor

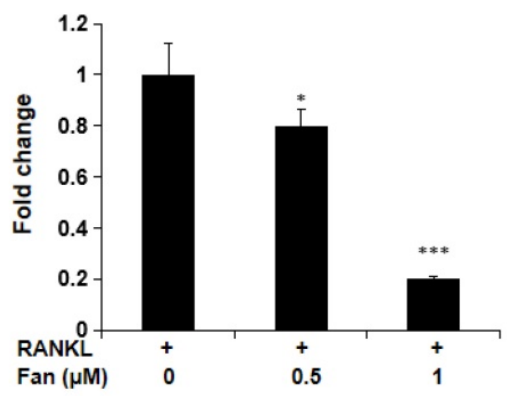

NFATc1

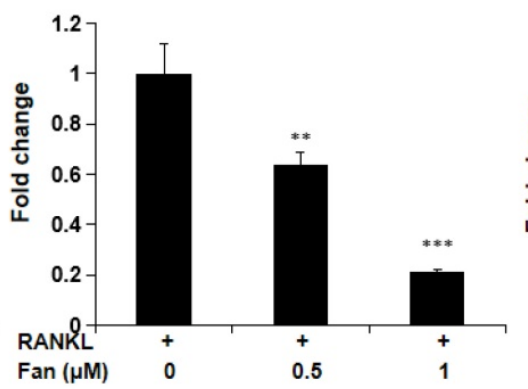

V-ATPase-d2

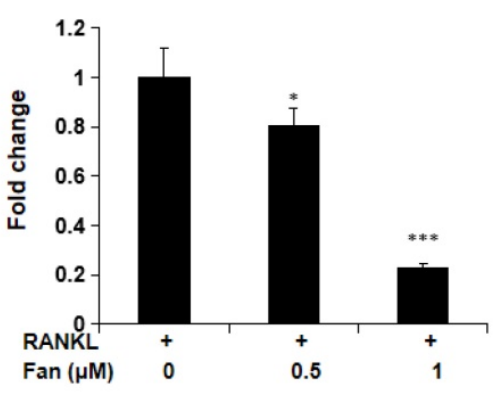

TRAcP

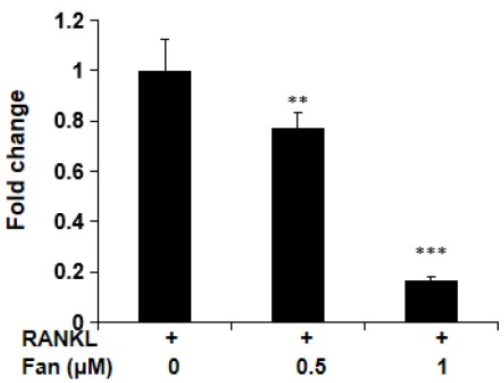

Figure 3. qPCR assay for osteoclast marker genes. BMMs were cultured with fangchinoline and RANKL for 5 days. Then, total RNA was extracted for cDNA transcription and qPCR was performed for determining the expression of osteoclast marker genes. The results showed that fangchinoline significantly inhibited the gene levels of Ctsk (cathepsin K), Calcr (calcitonin receptor), Atp6v0d2 (v-ATPase-d2), Mmp9 (matrix metallopeptidase 9), Nfatcl (nuclear factor of activated T cells 1) and Acp5 (TRAcP). $* P<0.05$, ** $P<0.01$, *** $P<0.001$ relative to fanchinoline-untreated controls. 


\section{Fangchinoline inhibits NF-KB activity, but not IKB $\alpha$ degradation and the MAPK pathway}

To further study the molecular mechanism by which fangchinoline inhibits osteoclastogenesis, luciferase and western blot assays were used. Luciferase assay showed that fangchinoline inhibits NF- $\mathrm{kB}$ activity at the dose of $1 \mu \mathrm{M}$ (Figure 4A). However, western blot results showed that ІкBa degradation was not affected by fangchinoline, suggesting that NF-KB activity was affected downstream of IKBa (Figure 4B). In addition, fangchinoline did not inhibit RANKL-induced phosphorylation of ERK1/2, P38 and JNK1/2 (Figure 5).

\section{Fangchinoline inhibits NFAT activity, and protein expression of NFATcl and V-ATPase-d2}

The effect of fangchinoline on NFAT activity was investigated by NFAT luciferase assay. RAW264.7 cells transfected with NFAT luciferase gene reporter construct were pre-treated with fangchinoline for $1 \mathrm{~h}$, and then incubated with RANKL (50 ng/ml) for $24 \mathrm{~h}$. The results showed that RANKL-induced NFAT activity was inhibited by fangchinoline from $0.5 \mu \mathrm{M}$ in a dose-dependent manner (Figure 6A). Consistently, the expression of NFATc1 protein was also inhibited by fangchinoline as shown by western blot analysis (Figure 6B, C). In addition, V-ATPase-d2, which is induced by NFATc1, was also inhibited by fangchinoline at $1 \mu \mathrm{M}$ (Figure 6B, C).

\section{Fangchinoline protects against OVX-induced bone loss}

To determine the effect of fangchinoline on osteoporosis-induced bone loss, OVX mice which imitate postmenopausal osteoporosis were used in this study. The mice were divided into four groups: sham group, OVX group, OVX + fangchinoline $(1 \mathrm{mg} / \mathrm{kg})$ group and OVX + fangchinoline $(5 \mathrm{mg} / \mathrm{kg})$ group. Each group contains 6 mice. Fangchinolinetreated mice had significantly increased bone mass from the 3D images (Figure 7A) and the bone parameters (Figure 7B) as determined by micro-CT. As shown in Figure 7B, fangchinoline-treated OVX mice had a dose dependent increase in BV/TV and Tb.N, and decrease in Tb.Sp. These results indicated that fangchinoline inhibits OVX-induced bone loss in a dose dependent manner.

A

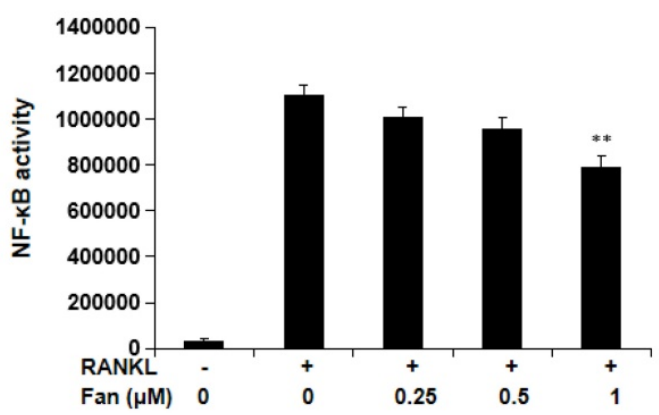

B

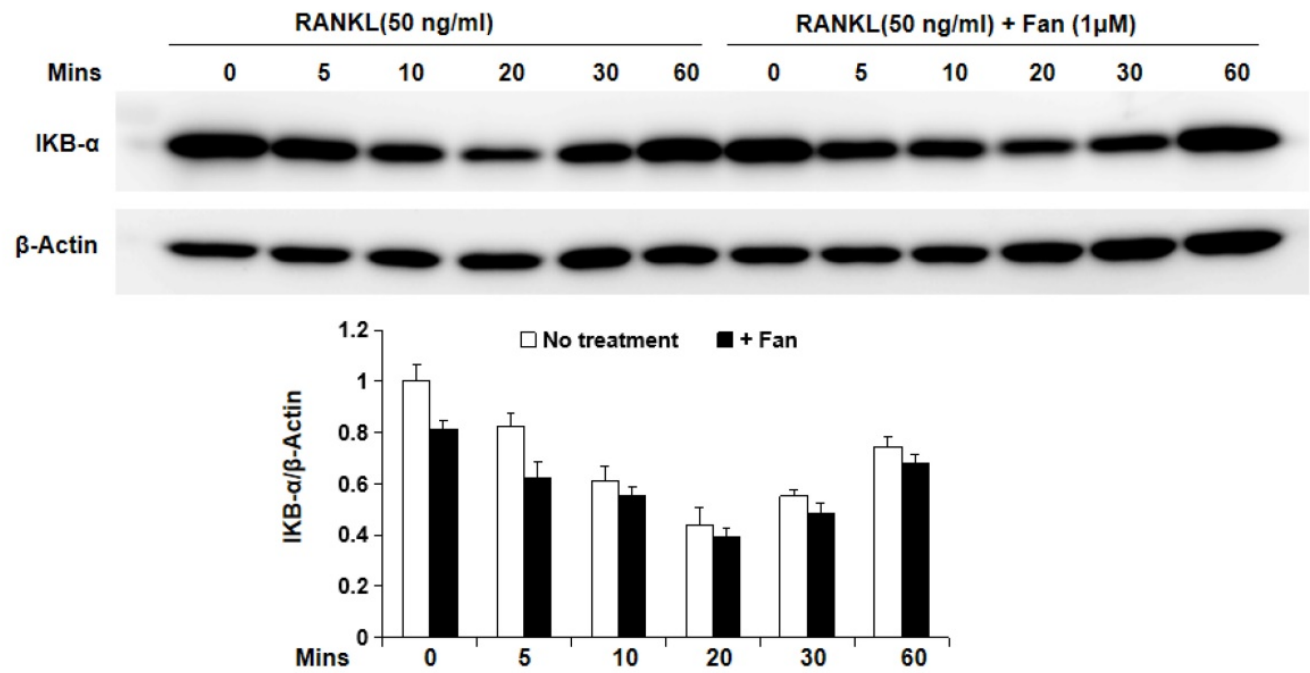

Figure 4. Fangchinoline suppresses RANKL-induced NF-KB activity, but not IKBa degradation. (A) NF-KB luciferase assay results suggested that fangchinoline reduced NF-KB activity at $1 \mu$. (B) BMM cells were pre-treated with fangchinoline for $1 \mathrm{~h}$, then stimulated by RANKL at different time points $(0,5,10$, $20,3060 \mathrm{~min}$ ), followed by harvested for WB assay. (C) The ratios of the density of IKB- $\alpha$ bands relative to $\beta$-actin bands were determined using Image J. $n=3$. The results showed that IKBa degradation was not affected by fangchinoline. $* * P<0.01$ relative to fanchinoline-untreated controls. 
A

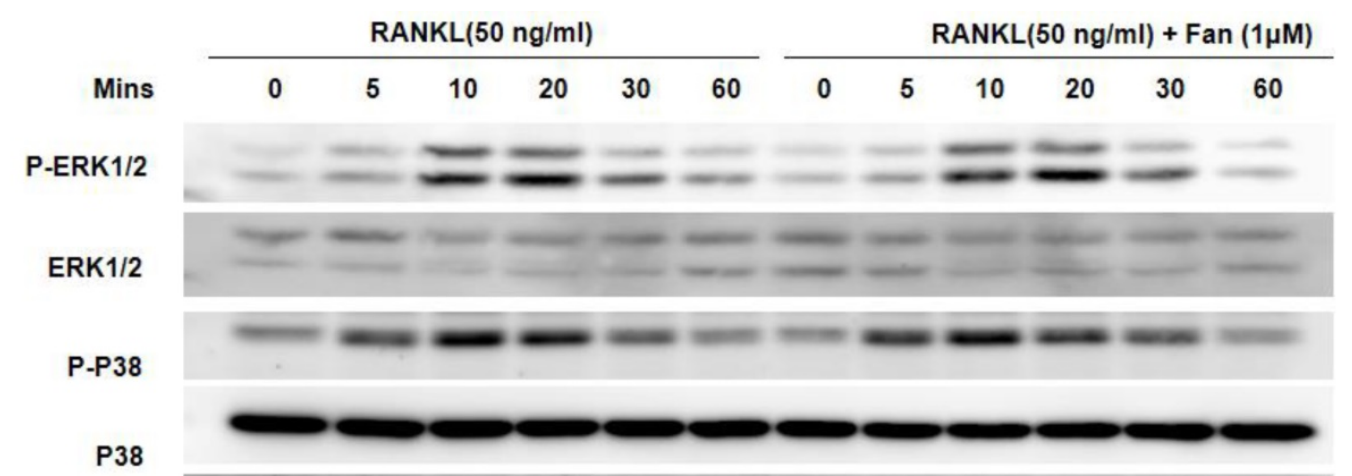

JNK1/2
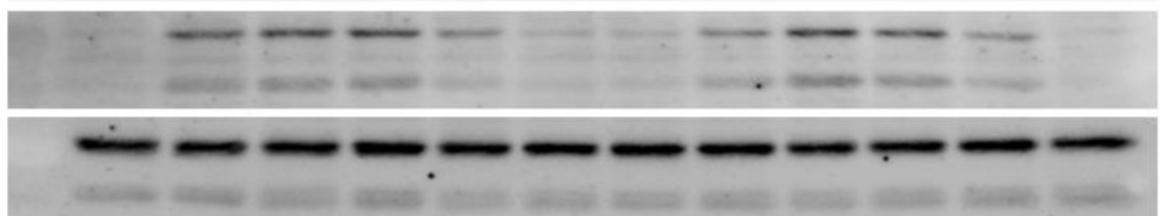

B

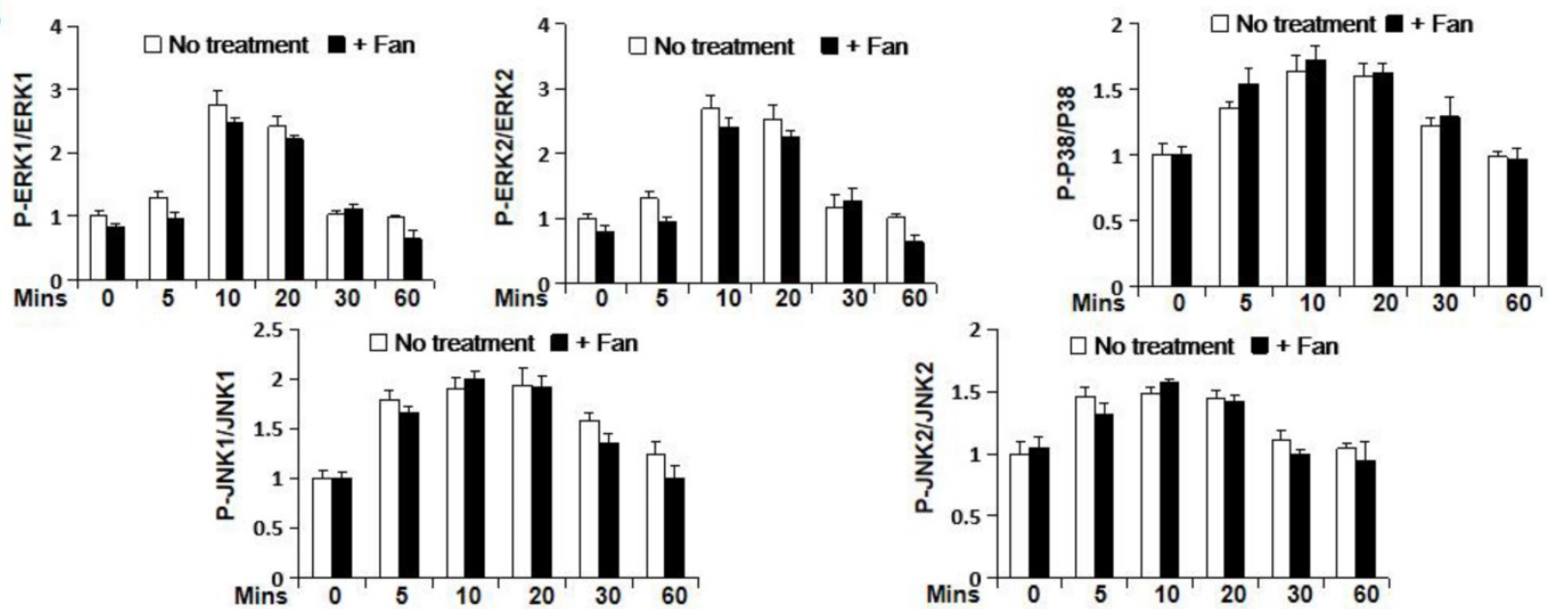

Figure 5. Fangchinoline doesn't affect RANKL-induced MAPK pathway. (A) Cells for detecting the effect of fangchinoline on MAPK pathway by WB assay were treated and harvested same as WB assay for assessing IKBa degradation. (B) The ratios of the density of P-ERK1/P-ERK2 bands relative to ERK1/ ERK2, P-P38 bands relative to $\mathrm{P} 38$ bands and P-JNK1/P-JNK2 bands relative to JNK1/JNK2 bands were determined using Image J. $\mathrm{n}=3$. The results showed that fangchinoline had no effect on the phosphorylation of ERK 1/2, P38 and JNK1/2, indicating the inhibitory fangchinoline on osteoclastogenesis was not through MAPK pathway. The results showed that IKBa degradation was not affected by fangchinoline.

Histology results further confirmed the protective effects of fangchinoline on osteoporosisinduced bone loss. As shown in Figure 8, BV/TV was significantly increased in fangchinoline treated OVX group compared with vehicle-treated OVX group. In addition, fangchinoline treated OVX group exhibited a significant reduction in osteoclast number/bone surface (N.Oc/Bs) and osteoclast surface/bone surface (Oc.S/BS) compared with vehicle-treated OVX group (Figure 8A, B), suggesting that fangchinoline protects against osteoporosis-induced bone loss through attenuating osteoclast activity.

\section{Discussion}

Osteoporosis is a common disease in elderly populations and may reduce life expectancy due to facture (14). The development of osteoporosis is associated with the overproduction and overactivity of osteoclasts (15). Current treatments against osteoporosis have some side effects, such as bisphosphonates-induced osteonecrosis of jaw and estrogen-induced breast cancer $(16,17)$. Natural compounds may provide an alternative treatment to osteoporosis since they have been considered to be relatively safer than pharmaceutical synthetic chemicals (18). Numerous natural compounds have been found to attenuate osteoporosis based on cell culture and animal experiments (19). In this study, we explored the therapeutic effect of fangchinoline on osteoclastogenesis and OVX-induced bone loss.

Previous studies have reported that fangchinoline has extensive pharmacological properties including anti-inflammatory (5), antioxidant (6), anti-tumour $(20,21)$, anti-HIV (22) and neural protection effects (23). In this study, we found that fangchinoline suppressed RANKL-induced osteoclast formation and function, and ameliorated bone loss in OVX mice. Our results are in line with 
previous report which showed that tetrandrine, an analogue of fangchinoline, suppressed RANKLinduced osteoclast differentiation and bone loss in sciatic-neurectomized mice (8).

Osteoclasts, arising from the monocytemacrophage lineage, are the specific cells, which contribute to bone resorption (24). RANKL and M-CSF are two critical cytokines for the formation and differentiation of osteoclasts. In this study, osteoclastogenesis was dose-dependently inhibited by fangchinoline in the presence of RANKL and M-CSF. MTS results suggested the fangchinoline exerts the inhibitory effect of osteoclastogenesis not through cytotoxicity. Consistently, fangchinoline also down regulated the expression of a series of osteoclasts marker genes, including Ctsk, Calcr, Atp6v0d2, Mmp9, Nfatc1 and Acp5.

The inhibitory effect of fangchinoline on osteoclasts function was studied in vitro using hydroxyapatite-coated plates, which mimics in vivo bone surface to study drug-affected cell functional activity. The hydroxyapatite resorption assay is a simple assay to quantitatively measure the osteoclastic resorbed area. Our results showed that fangchinoline significantly inhibited mature osteoclasts resorption at the concentration of 0.5 and 1 $\mu \mathrm{M}$, without affecting cell number. Bone resorption is a process that osteoclasts degrade bone and subsequently release calcium to blood (25). The increased bone resorption has critical involvement in the development of osteolytic diseases. Thus, the inhibiting effect of fangchinoline on bone resorption is essential for the potential role of treating osteoporosis. The active osteoclasts degrade inorganic mineral, mainly calcium and phosphate, through secreting acid from the ruffled border, and also dissolve organic matrix of bone, primarily type I collagen, by producing cathepsin K and MMPs (25), consistent with our results that fangchinoline down regulates the gene expression of Ctsk and Mmp9.

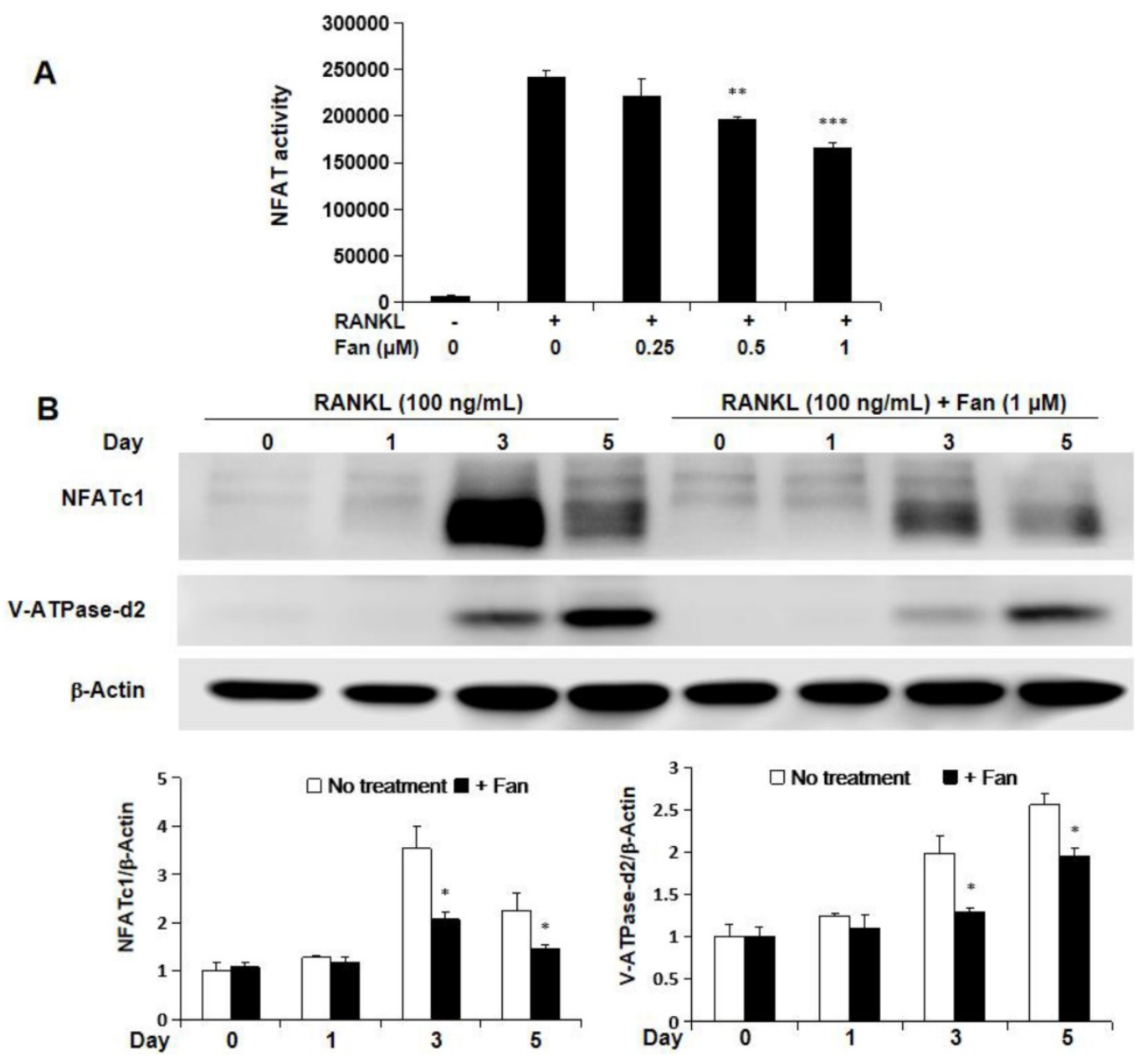

Figure 6. Fangchinoline inhibits NFAT activity, as wells as the expression of NFATcl and v-ATPase-d2. (A) NFAT luciferase results showed that fangchinoline inhibited NFAT activity from $0.5 \mu \mathrm{M}$ in a dose dependent manner. (B) BMMs were treated with fangchinoline for 5 days and stimulated with RANKL at day 1, 3 and 5. Then, WB assay was performed on the cell lysates. (C) The ratios of the density of NFATcl bands relative to $\beta$-actin bands and v-ATPase-d 2 relative to $\beta$-actin bands were determined using Image $\mathrm{J}$. $\mathrm{n}=3$. It was shown from results that the protein levels of NFATcl and $v$-ATPase-d 2 were significantly inhibited by fangchinoline at day 3 and 5 . $* P<0.05$, ** $P<0.01$, *** $P<0.001$ relative to fanchinoline-untreated controls. 
A

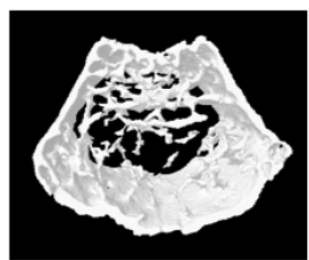

Sham

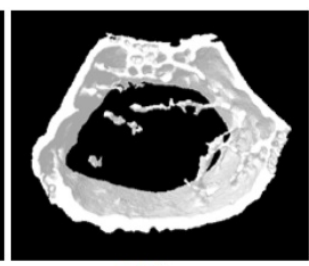

OVX

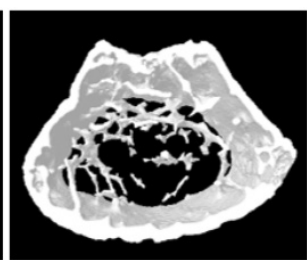

OVX + Fan $(1 \mathrm{mg} / \mathrm{kg})$

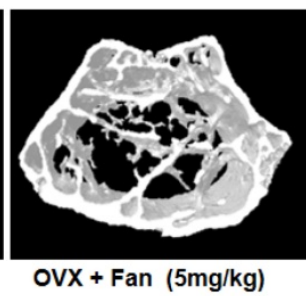

OVX + Fan $(5 \mathrm{mg} / \mathrm{kg})$
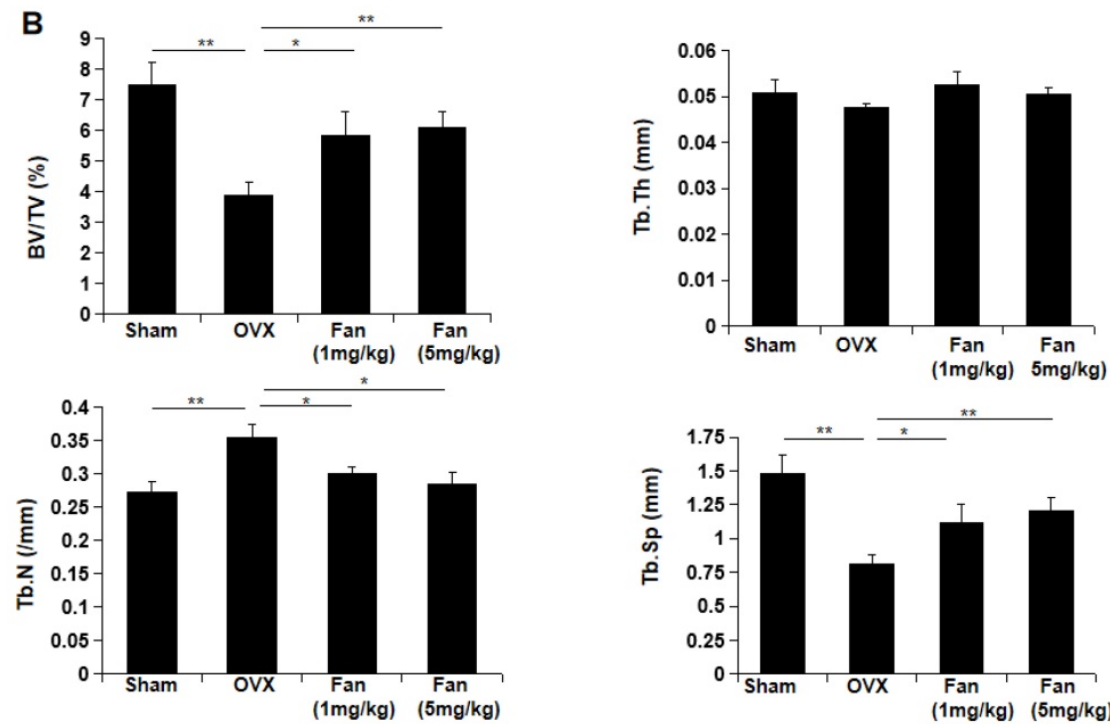

Figure 7. Fangchinoline protects against ovariectomy-induced bone loss. (A) Constructed 3D images of proximal femur from sham, OVX, OVX mice injected with low doses and high doses of fangchinoline. (B) The microstructure of bone mass was analysed by following parameters: BV/TV, Tb.Th, Tb.Sp and Tb.N. $* P<0.05, * * P<0.01$.

The interaction of RANKL and RANK recruits TRAF6, which is an adaptor protein from the TNF receptor-associated factor (TRAF) protein family, initiating a series of TRAF6 downstream signalling cascades, including NF-kB, NFATc1 and MAPK families (ERK, P38, JNK) (26). NF-kB has been a well-known transcription factor required for survival and differentiation of osteoclasts (27), and play an important role of osteolytic bone disease(28, 29). In our study, NF-kB activity was significantly inhibited by fangchinoline, suggesting the inhibitory effect of NF- $\mathrm{kB}$ activity contribute to part of the underlining mechanisms through which fangchinoline regulates osteoclastogenesis. However, fangchinoline had little effect on IKBa degradation, implying that fangchinoline inhibits NF-kB activity through other unknown regulatory events. In addition, fangchinoline did not affect the phosphorylation of ERK, P38 and JNK, suggesting that the inhibitory effect of fangchinoline on osteoclasts is not through MAPK signalling. NFATc1, a master transcription factor for osteoclastogenesis, could be induced by RANKL and auto-amplifies its own transcription. NFATc1 transcription is regulated by calcineurin which is a calcium and calmodulin dependent serine and threonine protein phosphatase (30). Our results showed that fangchinoline inhibited NFAT activity and also down regulated the expression of NFATc1 and V-ATPase-d2. V-ATPase-d2 is transactionally regulated by NFATc1 (10), and contributes to the fusion of osteoclasts (31).

The therapeutic effect of fangchinoline on in vivo bone loss was investigated by using OVX mice. The OVX animal model, which mimics estrogen withdrawal in postmenopausal women, is the most common experimental method for assessing bone microarchitectural structure of postmenopausal osteoporosis in response to drugs. The process of bone resorption at first surpasses bone formation after ovariectomy, causing the decline of bone mass. Before long, bone resorption and formation reach a new balance (32). In our study, fangchinoline protected the decrease of bone mass reflected by following parameters: the increased $\mathrm{BV} / \mathrm{TV}$ and $\mathrm{Tb} . \mathrm{N}$, and decrease Tb.Sp in OVX mice. In addition, bone histomorphometry results revealed that the protective effects of fanchinoline is through inhibiting the osteoclasts activity by the relative parameter such as osteoclast number/ bone surface (N.Oc/BS) and osteoclast surface/ bone surface (Oc.S/BS). Our results are in line with recent findings showing an inhibitory effect of tetrandrine on bone loss $(8,33)$, and also provide new mechanistic insights of fangchinoline. 
A
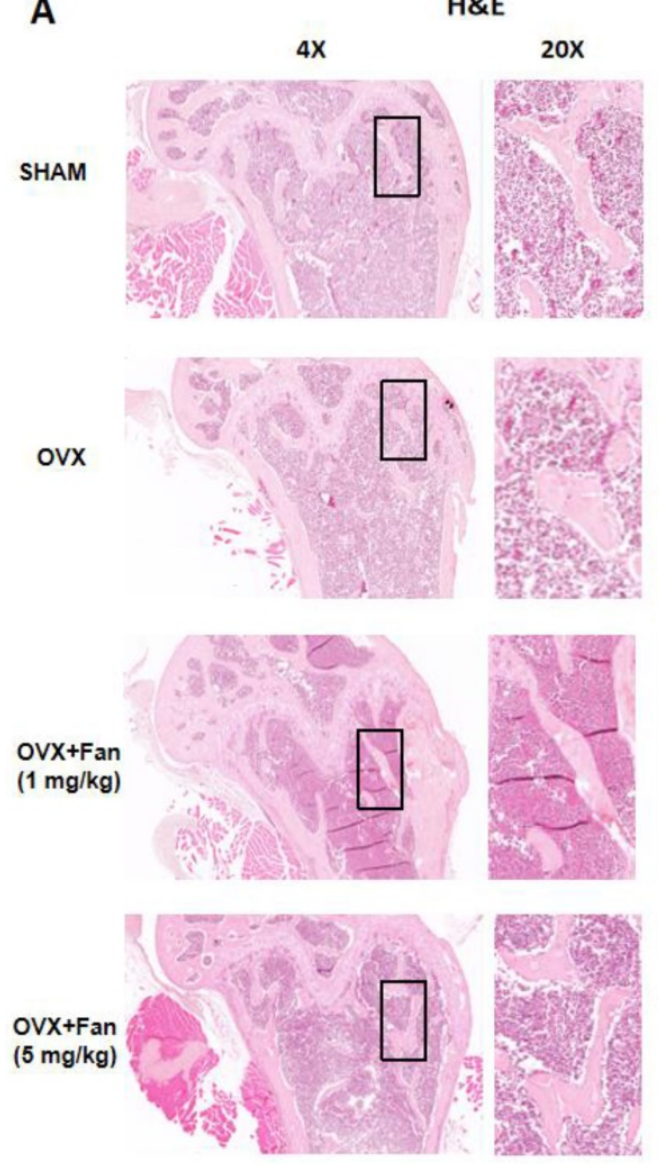

$H \& E$

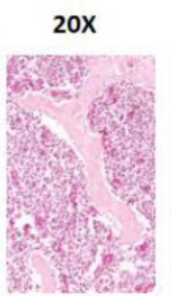

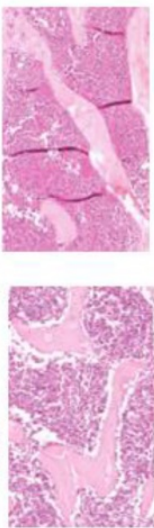

$4 \mathrm{X}$
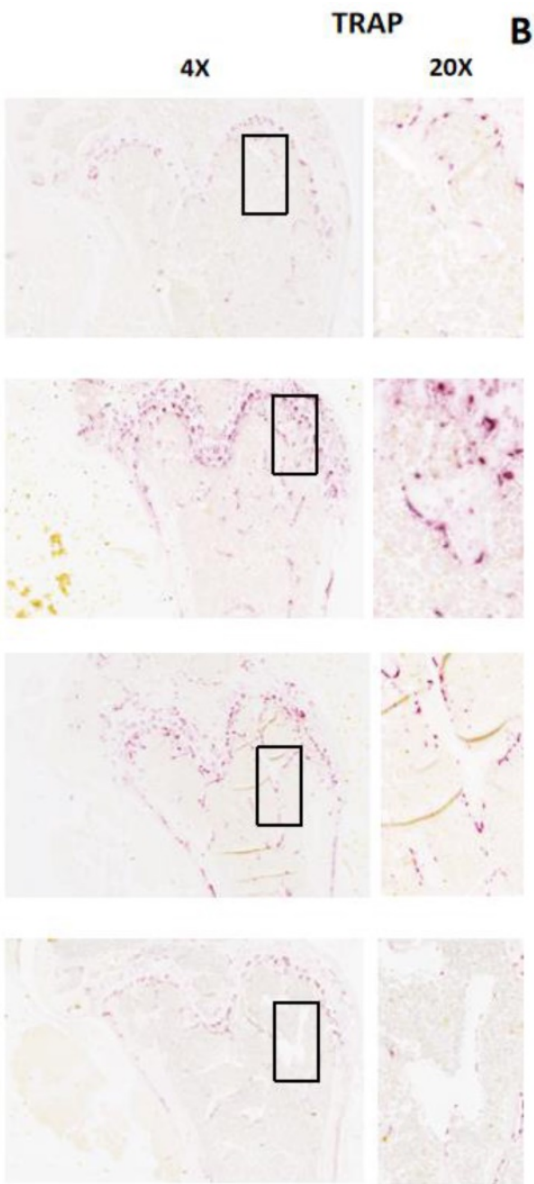
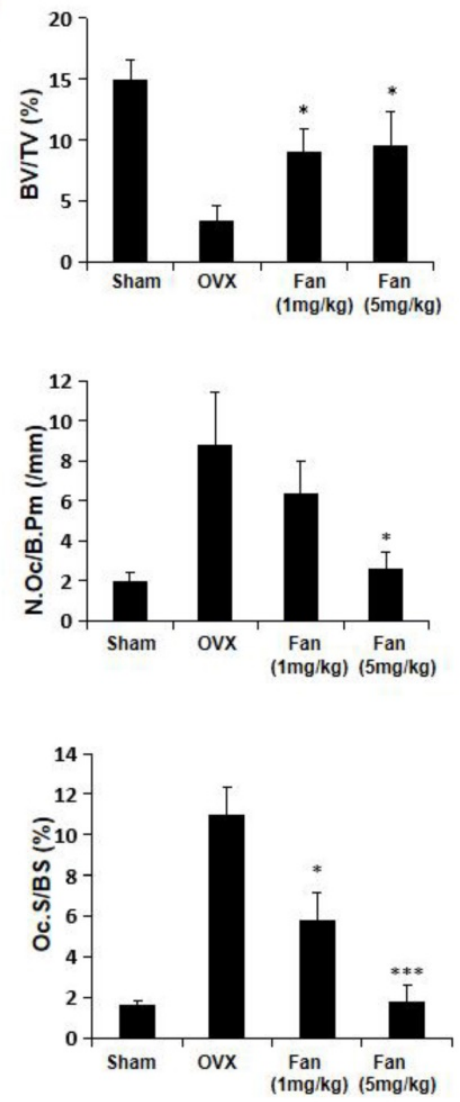

Figure 8. Fangchinoline protects against ovariectomy-induced bone loss via inhibiting osteoclast activity. (A) Representative images of decalcified bone stained with H\&E and TRAcP from sham, OVX, OVX + fangchinoline $(1 \mathrm{mg} / \mathrm{ml}), O V X+$ fangchinoline $(5 \mathrm{mg} / \mathrm{ml})$. (B) Quantitative analysis of bone volume/total volume (BV/TV), osteoclast surface/bone surface (Oc.S/BS), and osteoclast number/bone surface (N.Oc/BS). $n=3$. $* P<0.05$, $* * * P<0.001$ relative to $O V X$ untreated controls.

In conclusion, fangchinoline attenuated osteoclast formation, function and ameliorated OVX-induced osteoporosis in mice mainly through suppressing RANKL signalling pathways and osteoclast marker genes expression. Our results suggest that fangchinoline, as a natural compound is a potential candidate drug for the therapy of osteoporosis and other osteoclast-mediated bone diseases.

\section{Acknowledgements}

The authors acknowledge the support from Australian Health and Medical Research Council (NHMRC No. APP1107828, APP1127396, APP11271 56), Arthritis Foundation of Australia (The H J \&G J Mckenzie grant), Western Australia Medical \& Health Research Infrastructure Fund, University of Western Australia Research Collaboration Awards. This study was also funded in part by the Nature Science Foundation of Guangxi (2015GXNSFDA139019), Medical Scientific Research Foundation of Guangdong Province of China (A2019006), Guangzhou
Medical University Student Laboratory Open Project (2018) and Young innovative talents project of Guangdong Province (2017KQNCX167). This study was also supported by grants from the Guangdong Natural Science Foundation (No. 2018A030313248), the Fundamental Research Funds for the Central Universities in China (No.17ykpy49). The authors also acknowledge the facilities and technical assistance of the National Imaging Facility, a National Collaborative Research Infrastructure Strategy (NCRIS) capability, at the CMCA, The University of Western Australia (UWA). GH, SL, QL, and FS were visiting scholars to UWA.

\section{Author Contributions}

LZ and JX designed research; QL and FS analyzed data; LZ, GH, SL, FS, and JY performed research; LZ, GH, JT, JY and JX wrote and revised the paper; JZ contributed reagents or analytic tools.

\section{Competing Interests}

The authors have declared that no competing interest exists. 


\section{References}

1. McHugh KP, Hodivala-Dilke K, Zheng MH, Namba N, Lam J, Novack D, et al. Mice lacking beta3 integrins are osteosclerotic because of dysfunctional osteoclasts. The Journal of clinical investigation. 2000 Feb;105(4):433-40. PubMed PMID: 10683372. Pubmed Central PMCID: 289172. Epub 2000/02/23. eng.

2. Kular J, Tickner J, Chim SM, Xu J. An overview of the regulation of bone remodelling at the cellular level. Clinical biochemistry. 2012 Aug:45(12):863-73. PubMed PMID: 22465238.

3. Wada T, Nakashima T, Hiroshi N, Penninger JM. RANKL-RANK signaling in osteoclastogenesis and bone disease. Trends Mol Med. 2006 Jan;12(1):17-25. PubMed PMID: 16356770. Epub 2005/12/17. eng.

4. Huang KC. The Pharmacology of Chinese Herbs. Florida: CRC Press; 1993.

5. Choi HS, Kim HS, Min KR, Kim Y, Lim HK, Chang YK, et al. Anti-inflammatory effects of fangchinoline and tetrandrine. Journal of ethnopharmacology. 2000 Feb;69(2):173-9. PubMed PMID: 10687873. Epub 2000/02/25. eng.

6. Gulcin I, Elias R, Gepdiremen A, Chea A, Topal F. Antioxidant activity of bisbenzylisoquinoline alkaloids from Stephania rotunda: cepharanthine and fangchinoline. Journal of enzyme inhibition and medicinal chemistry. 2010 Feb;25(1):44-53. PubMed PMID: 20030508. Epub 2009/12/25. eng.

7. Abu-Ghefreh AA, Canatan H, Ezeamuzie CI. In vitro and in vivo anti-inflammatory effects of andrographolide. International immunopharmacology. 2009 Mar;9(3):313-8. PubMed PMID: 19110075. Epub 2008/12/27. eng.

8. Takahashi T, Tonami Y, Tachibana M, Nomura M, Shimada T, Aburada M, et al. Tetrandrine prevents bone loss in sciatic-neurectomized mice and inhibits receptor activator of nuclear factor kappaB ligand-induced osteoclast differentiation. Biological \& pharmaceutical bulletin. 2012;35(10):1765-74. PubMed PMID: 23037166. Epub 2012/10/06. eng.

9. Xu J, Tan JW, Huang L, Gao XH, Laird R, Liu D, et al. Cloning, sequencing, and functional characterization of the rat homologue of receptor activator of NF-kappaB ligand. Journal of bone and mineral research : the official journal of the American Society for Bone and Mineral Research. 2000 Nov;15(11):2178-86. PubMed PMID: 11092398. Epub 2000/11/25. eng.

10. Feng H, Cheng T, Steer JH, Joyce DA, Pavlos NJ, Leong C, et al. Myocyte enhancer factor 2 and microphthalmia-associated transcription factor cooperate with NFATc1 to transactivate the V-ATPase d2 promoter during RANKL-induced osteoclastogenesis. The Journal of biological chemistry. 2009 May 22;284(21):14667-76. PubMed PMID: 19321441. Pubmed Central PMCID: 2682914. Epub 2009/03/27. eng.

11. Wang $\mathrm{C}$, Steer JH, Joyce DA, Yip $\mathrm{KH}$, Zheng $\mathrm{MH}, \mathrm{Xu} J$. 12-O-tetradecanoylphorbol-13-acetate (TPA) inhibits osteoclastogenesis by suppressing RANKL-induced NF-kappaB activation. Journal of bone and mineral research : the official journal of the American Society for Bone and Mineral Research. 2003 Dec;18(12):2159-68. PubMed PMID: 14672351. Epub 2003/12/16. eng.

12. van der Kraan AG, Chai RC, Singh PP, Lang BJ, Xu J, Gillespie MT, et al. HSP90 inhibitors enhance differentiation and MITF (microphthalmia transcription factor) activity in osteoclast progenitors. The Biochemical journal. 2013 Apr 15;451(2):235-44. PubMed PMID: 23379601. Epub 2013/02/06. eng.

13. Hwang YP, Yun HJ, Kim HG, Han EH, Lee GW, Jeong HG. Suppression of PMA-induced tumor cell invasion by dihydroartemisinin via inhibition of PKCalpha/Raf/MAPKs and NF-kappaB/AP-1-dependent mechanisms. Biochemical pharmacology. 2010 Jun 15;79(12):1714-26. PubMed PMID: 20152819. Epub 2010/02/16. eng.

14. Pinkerton JV, Thomas S, Dalkin AC. Osteoporosis treatment and prevention for postmenopausal women: current and future therapeutic options. Clinical obstetrics and gynecology. 2013 Dec;56(4):711-21. PubMed PMID: 24100598. Epub 2013/10/09. eng.

15. Boyle WJ, Simonet WS, Lacey DL. Osteoclast differentiation and activation. Nature. 2003 May 15;423(6937):337-42. PubMed PMID: 12748652. Epub 2003/05/16. eng.

16. Lippuner K. The future of osteoporosis treatment - a research update. Swiss medical weekly. 2012;142:w13624. PubMed PMID: 22815185. Epub 2012/07/21. eng.

17. Rachner TD, Khosla S, Hofbauer LC. Osteoporosis: now and the future. Lancet. 2011 Apr 9;377(9773):1276-87. PubMed PMID: 21450337. Pubmed Central PMCID: 3555696. Epub 2011/04/01. eng.

18. He Y, Staser K, Rhodes SD, Liu Y, Wu X, Park SJ, et al. Erk1 positively regulates osteoclast differentiation and bone resorptive activity. PloS one. 2011;6(9):e24780. PubMed PMID: 21961044. Pubmed Central PMCID: 3178550. Epub 2011/10/01. eng.

19. Bai S, Hu Z, Yang Y, Yin Y, Li W, Wu L, et al. Anti-Inflammatory and Neuroprotective Effects of Triptolide via the NF-kappaB Signaling Pathway in a Rat MCAO Model. Anat Rec (Hoboken). 2016 Feb;299(2):256-66. PubMed PMID: 26575184. Epub 2015/11/18. eng.

20. Wang CD, Yuan CF, Bu YQ, Wu XM, Wan JY, Zhang L, et al. Fangchinoline inhibits cell proliferation via Akt/GSK-3beta/ cyclin D1 signaling and induces apoptosis in MDA-MB-231 breast cancer cells. Asian Pacific journal of cancer prevention : APJCP. 2014;15(2):769-73. PubMed PMID: 24568493. Epub 2014/02/27. eng.
21. Luo X, Peng JM, Su LD, Wang DY, Yu YJ. Fangchinoline inhibits the proliferation of SPC-A-1 lung cancer cells by blocking cell cycle progression. Experimental and therapeutic medicine. 2016 Feb;11(2):613-8. PubMed PMID: 26893655. Pubmed Central PMCID: 4734059. Epub 2016/02/20. Eng.

22. Wan Z, Lu Y, Liao Q, Wu Y, Chen X. Fangchinoline inhibits human immunodeficiency virus type 1 replication by interfering with gp160 proteolytic processing. PloS one. 2012;7(6):e39225. PubMed PMID: 22720080. Pubmed Central PMCID: 3374765. Epub 2012/06/22. eng.

23. Lin TY, Lu CW, Tien LT, Chuang SH, Wang YR, Chang WH, et al. Fangchinoline inhibits glutamate release from rat cerebral cortex nerve terminals (synaptosomes). Neurochemistry international. 2009 Jul;54(8):506-12. PubMed PMID: 19428795. Epub 2009/05/12. eng.

24. Yavropoulou MP, Yovos JG. Osteoclastogenesis--current knowledge and future perspectives. Journal of musculoskeletal \& neuronal interactions. 2008 Jul-Sep;8(3):204-16. PubMed PMID: 18799853. Epub 2008/09/19. eng.

25. Teitelbaum SL. Bone resorption by osteoclasts. Science. 2000 Sep 1;289(5484):1504-8. PubMed PMID: 10968780. Epub 2000/09/01. eng.

26. Jimi E, Akiyama S, Tsurukai T, Okahashi N, Kobayashi K, Udagawa N, et al. Osteoclast differentiation factor acts as a multifunctional regulator in murine osteoclast differentiation and function. J Immunol. 1999 Jul 1;163(1):434-42. PubMed PMID: 10384146. Epub 1999/06/29. eng.

27. Franzoso G, Carlson L, Xing L, Poljak L, Shores EW, Brown KD, et al. Requirement for NF-kappaB in osteoclast and B-cell development. Genes \& development. 1997 Dec 15;11(24):3482-96. PubMed PMID: 9407039. Pubmed Central PMCID: 316809. Epub 1998/02/07. eng.

28. $\mathrm{Xu} \mathrm{J}, \mathrm{Wu} \mathrm{HF}$, Ang ES, Yip K, Woloszyn M, Zheng MH, et al. NF-kappaB modulators in osteolytic bone diseases. Cytokine \& growth factor reviews. 2009 Feb;20(1):7-17. PubMed PMID: 19046922.

29. Rea SL, Walsh JP, Layfield R, Ratajczak T, Xu J. New insights into the role of sequestosome 1/p62 mutant proteins in the pathogenesis of Paget's disease of bone. Endocrine reviews. 2013 Aug;34(4):501-24. PubMed PMID: 23612225.

30. Takayanagi H. The role of NFAT in osteoclast formation. Annals of the New York Academy of Sciences. 2007 Nov;1116:227-37. PubMed PMID: 18083930. Epub 2007/12/18. eng.

31. Lee SH, Rho J, Jeong D, Sul JY, Kim T, Kim N, et al. v-ATPase V0 subunit d2-deficient mice exhibit impaired osteoclast fusion and increased bone formation. Nature medicine. 2006 Dec;12(12):1403-9. PubMed PMID: 17128270. Epub 2006/11/28. eng.

32. Lelovas PP, Xanthos TT, Thoma SE, Lyritis GP, Dontas IA. The laboratory rat as an animal model for osteoporosis research. Comparative medicine. 2008 Oct;58(5):424-30. PubMed PMID: 19004367. Pubmed Central PMCID: 2707131. Epub 2008/11/14. eng

33. Jia Y, Miao Y, Yue M, Shu M, Wei Z, Dai Y. Tetrandrine attenuates the bone erosion in collagen-induced arthritis rats by inhibiting osteoclastogenesis via spleen tyrosine kinase. FASEB journal : official publication of the Federation of American Societies for Experimental Biology. 2018 Jan 30:fj201701148RR. PubMed PMID: 29401630. 